\title{
Erratum to: Assessment of Alpine Wetland Dynamics from 1976-2006 in the Vicinity of Mount Qomolangma (Everest)
}

\author{
Yong Nie • Ainong Li
}

Published online: 23 August 2011

(C) Society of Wetland Scientists 2011

\section{Erratum to: Wetlands}

DOI 10.1007/s13157-011-0202-7

Kobresia littledalei and Carex moorcroftii wet meadow

\begin{abstract}
Acknowledgements The authors are thankful to Prof. Yili Zhang and Dr. Linshan Liu of IGSNRR, CAS for sharing their many ideas and constructive suggestions on this research. We thank Prof. Rongfu Huang of Northwest Institute of Plateau Biology, CAS for his help with species identification during field surveys and anonymous reviewers for their valuable comments on the original manuscript. This study was jointly supported by the National Basic Research Program of China (grant 2005CB422006), Institutional Consolidation for Coordinated and Integrated Monitoring of Natural Resources towards Sustainable Development and Environmental Conservation in the Hindu Kush-Karakoram-Himalaya Mountain Complex (grant 76444-000), and External Cooperation Program of CAS (grant GJHZ0954).
\end{abstract}

The online version of the original article can be found at http://dx.doi. org/10.1007/s13157-011-0202-7.

Y. Nie $(\triangle)$

Institute of Geographic Sciences and Natural Resources

Research (IGSNRR), Chinese Academy of Sciences (CAS),

11A Datun Road,

Beijing 100101, China

e-mail: nieyong@126.com

$\mathrm{Y} . \mathrm{Nie} \cdot \mathrm{A} . \mathrm{Li}$

Institute of Mountain Hazards and Environment,

Chinese Academy of Sciences,

No. 9, Section 4, South Renmin Road,

Chengdu 610041, China 